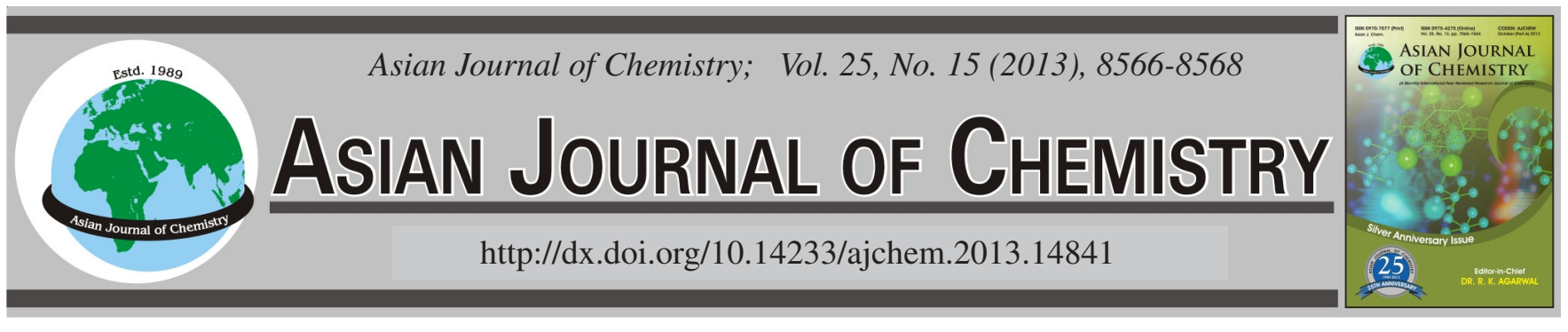

\title{
Synthesis and Crystal Structure of a Novel Homo[2]Heterocalix[2]arene[2]triazines containing Acridine Moiety
}

\author{
Rui-Xiao Wang, Lan Mu, Xi Zeng ${ }^{*}$, Qiang Sun, Yi Chen and Jun Li
}

Key Laboratory of Macrocyclic and Supramolecular Chemistry of Guizhou Province, Guizhou University, Guiyang 550025, P.R. China

*Corresponding author: Tel: +86 13985417193; E-mail: zengxi1962@163.com

\begin{abstract}
A novel homo[2]heterocalix[2]arene[2]triazine containing acridine moiety was synthesized and its structure was characterized by NMR, | IR and MS spectroscopy, its structure was confirmed by single crystal X-ray analysis. It's crystallization in the monoclinic system (space group, $\mathrm{P} 21 / \mathrm{n}$ ). It is clearly suggested that this compound was 1,3 -alternate conformation with $\mathrm{C}_{2 \mathrm{v}}$ symmetry. The multiple intermolecular hydrogen bond interactions led to the formation of an infinite one-dimensional chain structure and a two-dimensional zigzag layered structure.

Key Words: Heterocalixaromatics, Crystal structure, 1,3-Alternate conformation.
\end{abstract}

\section{INTRODUCTION}

Calix[n]arenes play an important role in supramolecular chemistry because of their easy availability, unique conformational and cavity structures and versatile molecular recognition properties. They have been widely used as molecular platforms and host molecules in the research of fluorescent porbes ${ }^{1}$. Recent years, a venerable family of calixarenes incorporating heteroaromaticarene units in the calixarene framework, have attracted particularly interesting for their peculiar supramolecular receptor properties ${ }^{2}$. Through substitution of their methylene bridge with heteroatoms (such as nitrogen, oxygen) or to replace of classic aromatics with heterocyclic or polycyclic ring aromatics (such as pyridine, triazine). They can form fine-tunable conformation, cavity structures and producing the cavity of varied electronic features. Many heterocalixaromatics have been shown excellent recognition abilities to cations, anions and neutral molecules. To enlarge the heterocalixaromatics' cavity and varied conformations by insert methylene units into the bridging position of heterocalixaromatics, we can get a new generation of calixareneshomoheterocalixaromatics, Wang and coworker ${ }^{3}$ already synthesis of some homo heterocalixaromatics, but the study on it's recognition abilities especially the application as fluorescent probe is still rare.

To explore their applications in molecular recognition and molecular assembly. Herein, we reported the synthesis of novel homo[2]heterocalix[2] arene[2] triazines containing acridine moiety (compound $\mathbf{1}$ ) through the fragment coupling synthesis method. the synthetic route of compound $\mathbf{1}$ as shown in Scheme-I.

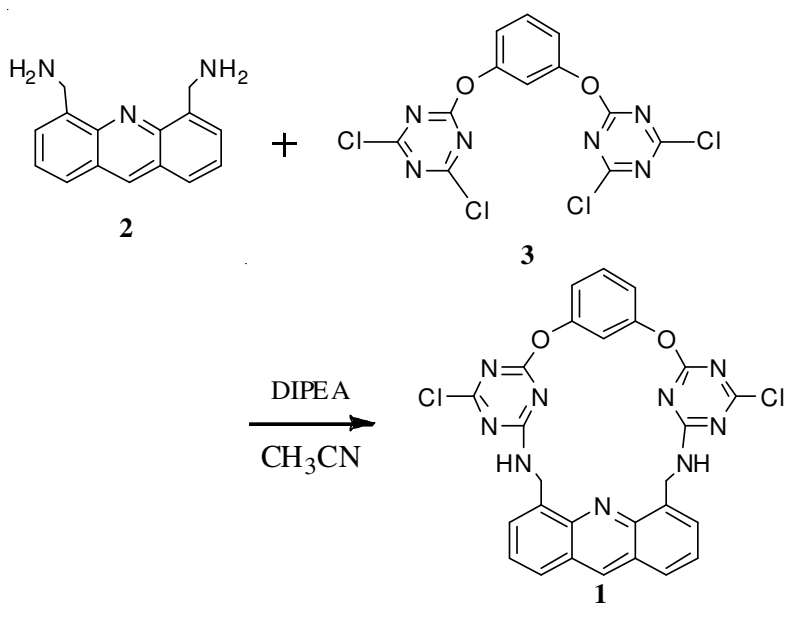

Scheme-I: Synthesis of compound $\mathbf{1}$

\section{EXPERIMENTAL}

${ }^{1} \mathrm{H}$ NMR spectra were measured on a Varian Nova-400 NMR spectrometer at room temperature using TMS as an internal standard. ESI-MS spectra was recorded on an Agilent HPLC-MSD-Trap-VL spectrometer. Crystal X-ray diffraction was conducted on a Bruker Smart ApexII CCD diffractometer. The $\mathrm{X}$-ray datas were collected with graphite-Monochromated $\operatorname{MoK}_{\alpha}$ radiation $(\lambda=0.071073 \AA)$ in $\phi$ and $\omega$ scan modes. The structure was solved by direct methods using SHELX-97 software 
packages. IR spectra were obtained using a Bruker Vertex 70 FT-IR spectrometer. The melting points were measured by an X-5 (Beijing Tech. Instrument Co., China) apparatus and are uncorrected.

Synthesis of compound 2 and 3: Compoud 2 and 3 were sythesized following the literature procedures ${ }^{4,5}$.

Synthesis of compound 1: At room temperature, solutions of 2 (100 mg, $0.42 \mathrm{mmol})$ in acetonitrile $(80 \mathrm{~mL})$ and $\mathbf{3}(171$ $\mathrm{mg}, 0.42 \mathrm{mmol})$ in acetonitrile $(80 \mathrm{~mL})$ were added dropwise at the same time and the same rate to a solution of DIPEA (135 mg, $10.5 \mathrm{mmol}$ ) in $100 \mathrm{~mL}$ acetonitrile during $6 \mathrm{~h}$. Then continue to react $48 \mathrm{~h}$ at same temperature. TLC monitoring until starting materials were consumed. The solvent was removed and the residue was chromatographied with chloroform/acetone $(20: 1, \mathrm{v} / \mathrm{v})$ as the mobile phase to give light yellow solid $157 \mathrm{mg}$, yield $24 \%$. m.p. > $320{ }^{\circ} \mathrm{C} ;{ }^{1} \mathrm{H}$ NMR $\left(\mathrm{DMSO}-d_{6}, 400 \mathrm{MHz}\right) \delta(\mathrm{ppm}) 9.545(\mathrm{t}, J=6.4 \mathrm{~Hz}, 2 \mathrm{H}), 9.156$ (s, 1H), $8.306(\mathrm{~s}, 1 \mathrm{H}), 8.098(\mathrm{dd}, J=2,1.6 \mathrm{~Hz}, 2 \mathrm{H}), 7.578-$ $7.622(\mathrm{~m}, 5 \mathrm{H}), 6.879(\mathrm{t}, J=2.4 \mathrm{~Hz}, 1 \mathrm{H}), 5.709$ (dd, $J=2.4$ $\mathrm{Hz}, 2 \mathrm{H}), 5.281(\mathrm{t}, J=8.0 \mathrm{~Hz}, 1 \mathrm{H}), 5.021(\mathrm{~m}, 2 \mathrm{H})$. IR $(\mathrm{KBr}$, $\left.\mathrm{V}_{\max }, \mathrm{cm}^{-1}\right): 3320,1608,1573,1521,1425,1384,1296,1240$, 1200, 1122, 992, 893, 804, 759, 570; calcd. (\%) analysis: C56.8 H3.0 Cl12.4 N22.1 O5.6; ESI-MS: $594.4\left(\mathrm{M}+\mathrm{H}^{+}+\mathrm{Na}^{+}\right)$.

\section{RESULTS AND DISCUSSION}

The single crystal of compound $\mathbf{1}$ was obtained by slowly evaporation of the solvent from its chloroform/ethanol solution at room temperature. Crystal X-ray diffraction was conducted on a Bruker Smart ApexII CCD diffractometer. The X-ray datas were collected with graphite-Monochro-mated $\mathrm{MoK}_{\alpha}$ radiation $(\lambda=0.071073 \AA)$ in $\phi$ and $\omega$ scan modes. The structure was solved by direct methods using SHELX-97 software packages.

The molecular structure for $\mathbf{1}$ is presented in Fig. 1, a selection of crystallographic data and bond distances/angles can be found in Tables 1 and 2. The crystal structure reveals that the compound $\mathbf{1}$ adopts a 1,3-alternate conformation with $\mathrm{C}_{2 \mathrm{v}}$ symmetry. the cavity of compoumd $\mathbf{1} \mathrm{cab}$ be viewed as being resultant from a cyclic array of two pieces of planar conjugated triazine segments and two isolated aromatic ring (acridine ring and benzene ring) in a 1,3-alternate fashion. four bridging atoms are located nearly in the same plane of trapezoidal owing to the acridine ring larger than the benzene ring. Among them, the acridine ring and benzene rings in
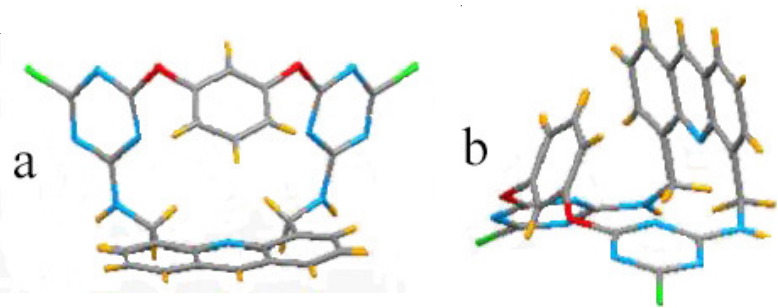

Fig. 1. Single crystal structure of compound 1: (a) top view and (b) side view

compoumd 1 nearly paralleled stand up to the plane formed by two bridging oxygen atoms and two nitrogen atoms, however, because of the $\mathrm{C}-\mathrm{H}-\pi$ interaction between benzene ring and acridine ring that led to the shrinkage of the upper rim and the benzene ring more intilted towards acridine ring, the inclined angles of the benzene ring and acridine ring to the plane of heteroatom bridges were 75.41 and $74.40^{\circ}$, respectively. The distance between two atoms(carbon or nitrogen) of face-to-face allied acridine ring and benzene ring is from $3.706 \AA$ (low rim) to $4.937 \AA$ (upper rim). While a pair of opposite triazine rings were edge-to-edge orientated and tend to be roughly coplanar. The inclined angles of two triazine rings to the plane of heteroatom bridges were 24.89 and $28.33^{\circ}$, respectively. And the distance between two triazines rings is from $5.794 \AA$ (low rim) to $10.373 \AA$ (upper rim).

Careful scrutiny of both the bond lengths between heteroatom and its connecting (hetero)aromatic carbons and bond angles of bridging atoms indicate that heteroatoms form conjugation with a triazine ring rather than with the benzene ring. The nature of the bridging units influences the inclined angles of both benzene and triazine rings to the plane of heteroatom bridges. In other words, the cavity of the compound $\mathbf{1}$ was controlled by the nature of the bridging heteroatoms and methylene units between heteroatoms and acridine ring. We also studied the self-assembly of compound $\mathbf{1}$ in the solid state and found that it has different patterns of intermolecular hydrogen bonds. The multiple intermolecular hydrogen bond interactions led to the formation of an infinite one-dimensional chain structure and a two-dimensional zigzag layered structure, respectively (Fig. 2).

\section{Conclusion}

We have synthesized the first examples of homo[2]heterocalix[2] arene-[2]triazines contianing acridine moiety by stepwise

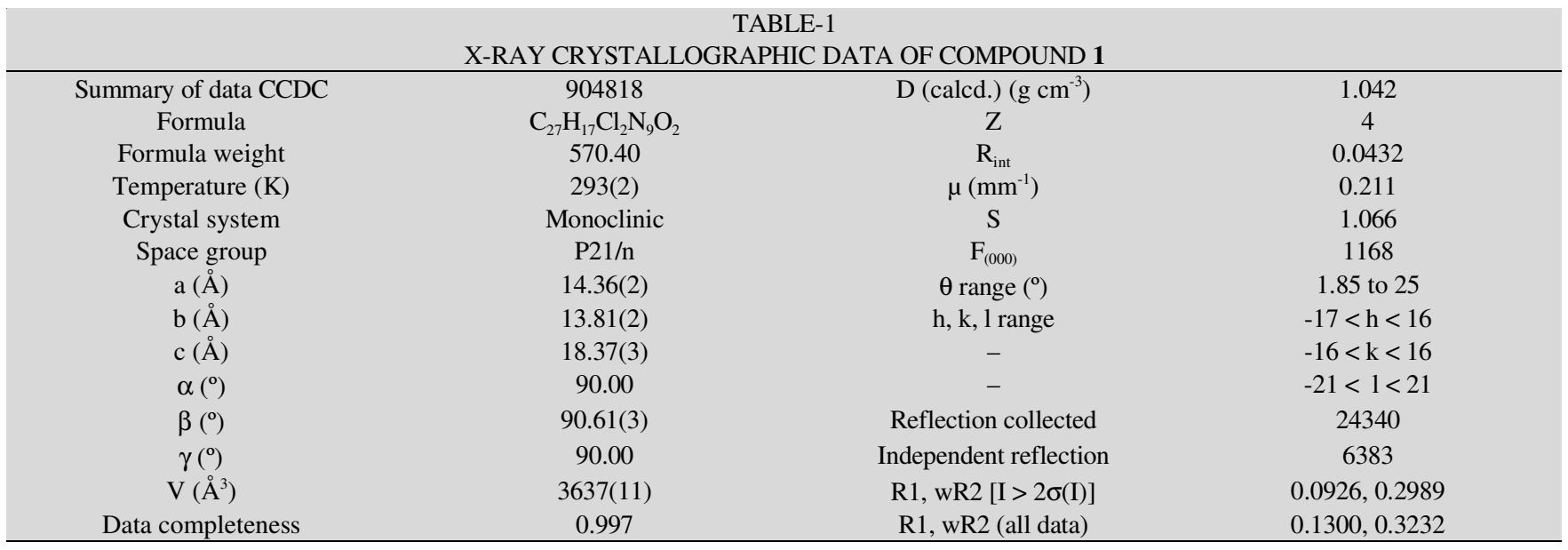



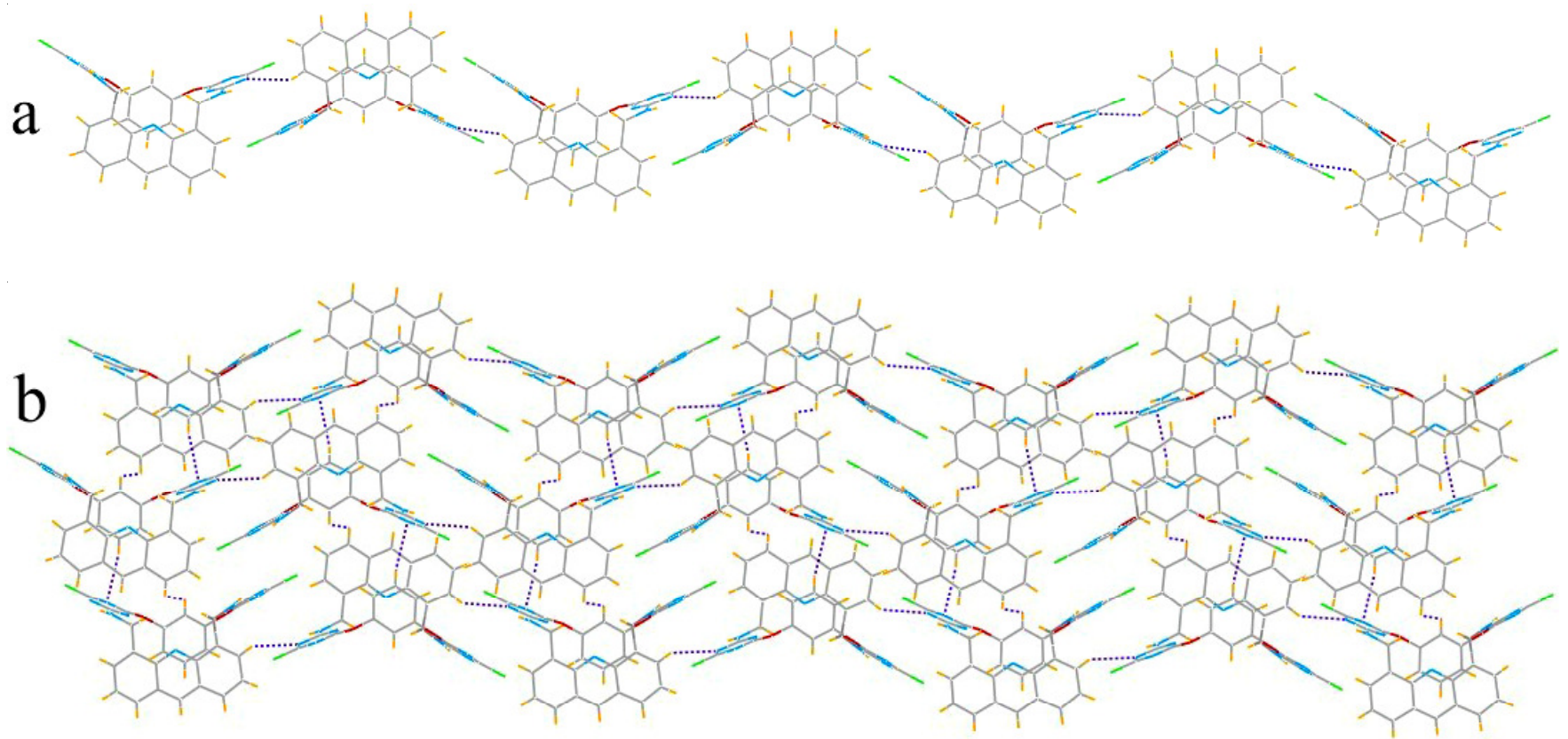

Fig. 2. Self-assembly of compound 1: (a) the self-assembly of compound $\mathbf{1}$ formed an infinite one-dimensional chain structure; (b) the self-assembly of compound 1 formed a two-dimensional zigzag layered structure

\begin{tabular}{|cclc}
\multicolumn{5}{c}{ TABLE-2 } \\
\multicolumn{4}{|c}{ SELECTED BOND DISTANCES $(\AA)$ AND ANGLES $\left({ }^{\circ}\right)$} \\
\hline $\mathrm{N}(8)-\mathrm{C}(15)$ & 1.4525 & $\mathrm{O}(2)-\mathrm{C}(22)$ & 1.4266 \\
$\mathrm{~N}(8)-\mathrm{C}(19)$ & 1.3255 & $\mathrm{Cl}(1)-\mathrm{C}(20)$ & 1.7354 \\
$\mathrm{~N}(9)-\mathrm{C}(14)$ & 1.4645 & $\mathrm{Cl}(2)-\mathrm{C}(17)$ & 1.7563 \\
$\mathrm{~N}(9)-\mathrm{C}(16)$ & 1.3758 & $\mathrm{C}(14)-\mathrm{N}(9)-\mathrm{C}(16)$ & 120 \\
$\mathrm{C}(1)-\mathrm{C}(15)$ & 1.5260 & $\mathrm{C}(15)-\mathrm{N}(8)-\mathrm{C}(19)$ & 120 \\
$\mathrm{C}(12)-\mathrm{C}(14)$ & 1.5195 & $\mathrm{C}(12)-\mathrm{C}(14)-\mathrm{N}(9)$ & 109.4 \\
$\mathrm{O}(1)-\mathrm{C}(18)$ & 1.3610 & $\mathrm{C}(1)-\mathrm{C}(15)-\mathrm{N}(8)$ & 109.4 \\
$\mathrm{O}(1)-\mathrm{C}(26)$ & 1.4347 & $\mathrm{C}(21)-\mathrm{O}(2)-\mathrm{C}(22)$ & 118.6 \\
$\mathrm{O}(2)-\mathrm{C}(21)$ & 1.3737 & $\mathrm{C}(18)-\mathrm{O}(1)-\mathrm{C}(26)$ & 118.4 \\
\hline
\end{tabular}

fragment coupling method under very mild conditions. The readily tunable cavity structures and the unique electronic feature of the surface of the cavity, i.e., 1,3-alternative electron-rich and electron-deficient $\pi$-aromatics, should render homo[2]heterocalix[2] arene[2]triazines and it's derivatives intriguing macrocyclic host molecules in the study of molecular recognition. It's applications in molecular recognition act as fluorescence probe are being actively investigated in this laboratory.

\section{ACKNOWLEDGEMENTS}

The authors are grateful for the financial support from the Fund of the International cooperation projects of Guizhou Province (No. 20107002), "Chun-Hui" Fund of Chinese of Education (No. Z2009-1-52001), Natural Science Foundation of China (No. 21165006).

\section{REFERENCES}

1. J.S. Kim and D.T. Quang, Chem. Rev., 107, 3780 (2007); B. Mokhtari and K. Pourabdollah, Asian J. Chem., 25, 1 (2013).

2. M.X. Wang, Chem. Commun., 4541 (2008).

3. Y. Chen, D.X. Wang, Z.T. Huang and M.X. Wang, J. Org. Chem., 75, 3786 (2010).

4. L.C. Marie, Y.M. Kim, B. Brassart, J.F. Riou, J.Y. Laronze and J. Sapi, Eur. J. Med. Chem., 44, 3880 (2009).

5. M.X. Wang and H.B. Yang, J. Am. Chem. Soc., 126, 15412 (2004). 